\title{
Impact of glutathione enriched Inactive Dry Yeast preparations on the stability of terpenes during model wine aging
}

Juan José Rodríguez-Bencomo a , Inmaculada Andújar-Ortiz a , M. Victoria MorenoArribas a , Carolina Simó a, Javier González ${ }^{\text {b }}$, Antonio Chana ${ }^{\mathrm{b}}$, Juan Dávalos ${ }^{\mathrm{b}}$, M. Ángeles Pozo-Bayón ${ }^{\text {a } *}$

${ }^{\text {a }}$ Instituto de Investigación en Ciencias de la Alimentación (CIAL) (CSIC-UAM).

C/ Nicolás Cabrera, 9, Campus de la Universidad Autónoma de Madrid, Cantoblanco, 28049, Madrid, Spain.

${ }^{\mathrm{b}}$ Instituto de Química-Física Rocasolano (CSIC)

C/ Serrano 119, 28006, Madrid (Spain)

*Corresponding author: Phone: +34 910017 961; Fax:+34 910017 905; Email:

$\underline{\text { m.delpozo@csic.es }}$ 
The impact of the addition of glutathione enriched Inactive Dry Yeast Preparations (gIDYs) on the stability of some typical wine terpenes (linalool, $\alpha$-terpineol, $\beta$-citronellol and nerol) stored under accelerated oxidative conditions was evaluated in model wines. Additionally, the effects of a second type of IDY preparation with a different claim (fermentative nutrient) and the sole addition of commercial glutathione into the model wines were also assessed. Model wines were spiked with the low molecular weight fraction $(<3 \mathrm{kDa}$ permeate) isolated from the IDYs, avoiding the interaction of aroma compounds with other yeast components. An exhaustive chemical characterization of both IDY permeates was carried out by using targeted and non-targeted metabolomics approaches using CE-MS and FT-ICR-MS analytical platforms. Our findings suggest that the addition of $<3 \mathrm{kDa}$ permeate isolated from any of the IDYs employed decrease the loss of typical wine terpenes in model wines submitted to accelerated aging conditions. The g-IDY preparation did indeed release reduced GSH into the model wines, although this compound did not seem exclusively related to the protective effect on some aroma compounds determined in both model wines. The presence of other sulphur-containing compounds from yeast origin in g-IDY, but also the presence of small yeast peptides, such as methionine/tryptophan/tyrosine containing tripeptide in both types of IDYs, seemed to be related to the antioxidant activity determined in the two permeates and in the minor loss of some terpenes in the model wines spiked with them.

Keywords: Inactive Dry Yeast Preparations, Glutathione, Terpenes, Wine oxidation, EC-MS, FT-ICR MS 
INTRODUCTION

57 During wine aging, oxidation can be an undesirable process responsible for important changes in the sensory characteristics of wines, especially in white wines. The loss of pleasant aromatic notes produced as a consequence of the decrease of important aroma compounds such as polyfunctional thiols, terpenes, esters, etc. ${ }^{1-3}$ and the accumulation of other undesirable compounds (hydrogen sulphide, methyl mercaptans) ${ }^{4}$ in wines with low exposure to oxygen, which produce the so-called "reduced off flavour", are mainly responsible for the depreciation on the quality of the wines.

Sulphur dioxide $\left(\mathrm{SO}_{2}\right)$ is the most common preservative used in winemaking, not only because of its antioxidant and antioxidasic properties, but also because of its antimicrobial action. However, due to existing health concerns derived from the consumption of high concentrations of sulphites, there is a current trend to limit its use during winemaking ${ }^{5}$. Therefore, different strategies focused on keeping the original aroma characteristics of young wines while aging in the bottle have been proposed. It has been shown that the addition of some sulphur containing compounds prior to wine bottling might preserve the degradation of certain aromas. Among others, it has been suggested that the addition of gluthatione ( $\gamma$-L-glutamyl-L-cysteinylglycine, GSH) at 10 $\mathrm{mg} / \mathrm{L}$ prior bottling might reduce the loss of 3-methylmercaptohexanol in Sauvignon 74 white wines ${ }^{6}$. More recently, Ugliano and collaborators ${ }^{4}$ remarked that GSH effectiveness might depend on other wine compositional parameters (e.g. the presence of copper reduces the GSH effect). The protective effect of GSH has also been shown against the loss of some ester and terpene compounds ${ }^{7-9}$, which are important contributors to pleasant floral and fruity notes in white wines ${ }^{3}$. This effect has been ascribed to the GSH free sulfhydryl (SH) moiety, which confers unique redox and 
nucleophilic properties ${ }^{10-13}$. It has also been found that GSH mixed with some wine polyphenols (caffeic and gallic acids) or other sulphur-containing compounds, such as $\mathrm{N}$-acetyl-cysteine, also have a protective effect against wine aroma oxidation ${ }^{14,15}$.

In spite of these promising results, the addition of GSH to the wine prior to bottling is a winemaking practice under study by the International Organization of Vine and Wine (OIV). However, other alternatives, such as the use of GSH-enriched Inactive Dry Yeast (g-IDY) preparations could be used to increase the levels of GSH in musts and wines ${ }^{16}$. The so-called IDY preparations are yeast derivatives obtained from Saccharomyces cerevisiae grown in a highly concentrated sugar medium and subsequently submitted to different inactivation treatments and manufacturing processes to obtain a variety of commercialized products (inactive yeast, yeast autolysates, yeast walls, and yeast extracts) ${ }^{16}$. The use of IDYs is gaining interest within the wine industry because of their large amount of potential applications in winemaking. Among them, as a consequence of its high content in GSH, g-IDYs have been claimed to preserve wine aroma and color during wine storage. However, although, as it has been recently stated, ${ }^{17}$ no literature could be found on the industrial preparation of $\mathrm{g}$-IDYs ${ }^{15}$, and it is still not clear whether exogenous GSH enrichment is allowed during the manufacturing process, the release of reduced GSH (the form active against oxidation) into the wines has been recently proven ${ }^{18,19}$. However, the effectiveness of the GSH released by these preparations on wine oxidation inhibition has not yet been investigated. Andujar-Ortíz and collaborators ${ }^{20}$ recently revealed significant differences between rosé Grenache wines produced by using a g-IDY preparation and non-treated wines in some sensory aroma attributes but only after 9 months of wine aging. This effect could be attributable to the GSH released from IDY or to the stimulating effect of amino acids and other 
104

105

106

107

108

109

110

111

112

113

peptides from the IDY on the GSH synthesis by yeast under winemaking conditions ${ }^{18}$, 19.

Considering the current interest of the wine industry in the use of g-IDY preparations to preserve the aroma of wines, and the lack of published literature on this topic, the aim of this work was to evaluate the effect of a g-IDY preparation on some typical and desirable wine aroma compounds (linalool, $\alpha$-terpineol, $\beta$-citronellol and nerol) by using model wines submitted to accelerated oxidative conditions. The effect of a second type of IDY preparation with a different claim (fermentative nutrient) and the effect of commercial GSH were also evaluated. To further understand the role of GSH from the IDY formulations, the wines were spiked with the low molecular weight fraction $(<3$ $\mathrm{kDa}$ ) obtained by cold-ultracentrifugation avoiding the interaction of other yeast components (glycoproteins) with the aroma compounds ${ }^{21,22}$. To conclude, chemical characterization of both IDY permeates $(<3 \mathrm{kDa}$ fraction) was carried out by using targeted and non-targeted metabolomic approaches using Fourier transform ion cyclotron resonance mass spectrometry (FT-ICR-MS) and capillary electrophoresismass spectrometry (CE-MS) analytical platforms.

\section{MATERIALS AND METHODS}

\section{IDY samples}

Two types of oenological IDY preparations were selected for being representative of the current preparations in the oenological market and because they are widely used in winemaking: a GSH-enriched IDY (g-IDY) recommended to reduce the oxidation of wine aroma compounds because of the presence of higher amounts of GSH, and a IDY preparation commonly used as fermentation nutrient (n-IDY). The comparison between 
both types of IDYs (with and without GSH in their composition) should better provide evidences about the role of GSH released by IDY in wine aroma oxidation.

Four grams of each IDY powder were weighed into 50-mL centrifuge tubes. Samples were extracted with $50 \mathrm{~mL}$ water-ethanol solution $(87: 13, \mathrm{v} / \mathrm{v})$ in an ultrasonic bath $(3$ cycles, $5 \mathrm{~min}$. each) at $4^{\circ} \mathrm{C}$. The mixture was then centrifuged ( $15 \mathrm{~min}$. at $5000 \mathrm{~g}$ and 10 ${ }^{\circ} \mathrm{C}$ ) and the supernatant was ultrafiltrated using a Centricon device (Amicon Inc., Beverly, MA, USA) with a $10 \mathrm{kDa}$ cut-off membrane. The obtained permeates were submitted to a second ultrafiltration step through a $3 \mathrm{kDa}$ cut-off membrane Centricon (Amicon Inc.). Both ultrafiltration steps were carried out at cold temperature (below 10 $\left.{ }^{\circ} \mathrm{C}\right)$. The obtained $<3 \mathrm{kDa}$ permeates from each IDY preparation were freeze-dried and membrane from Spectrum (Breda, The Netherlands) to remove salts.

\section{Model wine solutions under accelerated aging conditions}

Model wine solutions $(50 \mathrm{~mL})$ were prepared in $100 \mathrm{~mL}$ vials by adding ethanol (VWR, Leuven, Belgium) at $120 \mathrm{~mL} / \mathrm{L}$ and $4 \mathrm{~g} / \mathrm{L}$ tartaric acid (Panreac, Barcelona, Spain). The $\mathrm{pH}$ was adjusted at 3.5 using a $5 \mathrm{M} \mathrm{NaOH}$ solution (Panreac). Model wines were spiked with single terpene compounds (nerol, $\beta$-citronelol, $\alpha$-terpineol and linalool) from Sigma (Stenheim, Germany) at a final concentration of $25 \mathrm{mg} / \mathrm{L}$ each. Finally, $100 \mu \mathrm{L}$ of the reconstituted $<3 \mathrm{kDa}$ fractions isolated from g-IDY or $\mathrm{n}$-IDY at $100 \mathrm{mg} / \mathrm{mL}$, was added. In addition, another set of model wines were individually aromatised with the four aroma compounds and spiked with commercial GSH (Sigma) to a final 
151 concentration of $10 \mathrm{mg} / \mathrm{L}$. Finally, four control model wines, one with each aroma

152 compound, but without addition of the IDY fractions or commercial GSH were also

153 prepared. Two vials of the model wines containing each terpene compound were

154 analysed at the beginning of the experiment $(\mathrm{t}=0 \mathrm{~d})$. The different model wine mixtures

155 were submitted to an accelerated oxidation process during three weeks at $25{ }^{\circ} \mathrm{C}$

156 saturating the headspace of the vials with oxygen $(t=21 d)$. All the preparations were

157 carried out in duplicate.

\section{HS-SPME-GC/MS analysis}

159 Model wine aroma analysis was performed before ( $\mathrm{t}=0$ days) and after $(\mathrm{t}=21$ days) 160 model wine oxidation process. It was carried out by head space solid phase 161 microextraction coupled to gas chromatographymass spectrometry (HS-SPME$162 \mathrm{GC} / \mathrm{MS})$. Model wine samples $(8 \mathrm{~mL}), 2.3 \mathrm{~g}$ of $\mathrm{NaCl}$ and $40 \mu \mathrm{L}$ of an internal standards 163 solution (400 mg/L 3,4-dimethylphenol and $2.5 \mathrm{mg} / \mathrm{L}$ methyl nonanoate) were added to 164 a $20 \mathrm{~mL}$ SPME vial. The SPME procedure and chromatographic conditions were 165 detailed in a previous work ${ }^{23}$. Briefly, the extraction procedure was automatically performed using a CombiPal system (CTC Analytics AG, Zwingen, Switzerland) with a 50/30 $\mu \mathrm{m} \mathrm{DVB/CAR/PDMS} \mathrm{fibre} \mathrm{of} 2 \mathrm{~cm}$ length from Supelco (Bellefonte, CA, USA).

168 Samples were pre-incubated for $10 \mathrm{~min}$ at $50{ }^{\circ} \mathrm{C}$ and extraction was performed in the 169 headspace of each vial for $30 \mathrm{~min}$ at $50{ }^{\circ} \mathrm{C}$. Desorption was performed in the injector of 170 the GC system in splitless mode for $1.5 \mathrm{~min}$ at $270{ }^{\circ} \mathrm{C}$. After each injection the fibre was cleaned for 20 min to avoid any memory effect. The chromatographic separation was performed in a GC-MS instrument (Agilent6890GC, Agilent 5973 N MS) equipped with a Supra-Wax fused silica capillary column $(60 \mathrm{~m} \times 0.25 \mathrm{~mm}$ i.d. $\times 0.50 \mu \mathrm{m}$ film 174 thickness) from Konik (Barcelona, Spain). Helium was used as the carrier gas at a flow rate of $1 \mathrm{~mL} / \mathrm{min}$. The oven temperature was initially held at $40{ }^{\circ} \mathrm{C}$ for $5 \mathrm{~min}$, then, it 
increased at $4{ }^{\circ} \mathrm{C} / \mathrm{min}$ to $240{ }^{\circ} \mathrm{C}$, and held at $240{ }^{\circ} \mathrm{C}$ for $20 \mathrm{~min}$. The acquisitions were performed in scan (from 35 to $350 \mathrm{amu}$ ) and electronic impact mode $(70 \mathrm{eV})$. Other MS conditions were 270,150 and $230{ }^{\circ} \mathrm{C}$ for the transfer line, quadrupole and ion source respectively. The signal corresponding to a specific ion of quantification $(\mathrm{m} / \mathrm{z} \mathrm{93,} \mathrm{m} / \mathrm{z}$ 59, m/z 69, m/z 69 for linalool, $\alpha$-terpineol, $\beta$-citronellol and nerol, respectively) was calculated by the data system. The compound identification was carried out by comparison of retention times and mass spectra of the reference compounds with those reported in the mass spectrum library NIST 2.0. Data were obtained by calculating the relative peak area (RPA) in relation to that of the corresponding internal standard $(3,4-$ dimethylphenol, for all the aroma compounds except for nerol that was methyl nonanoate).

Analysis of reduced Glutathione (GSH), total Glutathione and $\gamma$-glutamylcysteine ( $\gamma$-glu-cys) by RP-HPLC-FL

Reversed-phase HPLC using a liquid chromatograph consisting of a Waters 600 Controller programmable solvent module (Waters, Milford, MA), a WISP 710B autosampler (Waters) and a HP 104-A fluorescence detector (Hewlett-Packard, Palo Alto, CA, USA) were used following the procedure previously optimised and validated 18. The mobile phase was composed of methanol (Lab-Scan, Sowinskiego, Poland) and aqueous solution of phosphate buffer $\left(10 \mathrm{mM} \mathrm{NaH}_{2} \mathrm{PO}_{4} \cdot 12 \mathrm{H} 2 \mathrm{O}\right.$ at $\left.\mathrm{pH} 8.5\right)$ with a ratio of 15:85 (v/v). The sample $(30 \mu \mathrm{L})$ was placed in a $1 \mathrm{~mL}$ vial (by using an insert) and the precolumn derivatization was automatically made in the autosampler at $12{ }^{\circ} \mathrm{C}$ as following: to a sample vial were added $105 \mu \mathrm{L}$ from the dithiotreitol (Sigma-Aldrich) solution vial [ $5 \mathrm{mM}$ and $0.5 \mathrm{mM}$ in borate buffer $\left(0.2 \mathrm{M} \mathrm{H}_{3} \mathrm{BO}_{4}, \mathrm{pH} 9.2\right)$ to determine total GSH or reduced GSH, respectively] and $15 \mu \mathrm{L}$ of 2,3-naphtalenedialdehyde (NDA) (Sigma-Aldrich) solution $\left(5 \mathrm{mg} \mathrm{mL}^{-1}\right.$ in ethanol); then, two mixtures cycles of 
201 the total content of the insert were carried out and $100 \mu \mathrm{L}$ were injected in the 202 chromatographic system. Separation was carried out on a Nova Pack C18 (150 mm x $3.9 \mathrm{~mm}$ i.d., $60 \mathrm{~A}, 4 \mu \mathrm{m}$ ) column (Waters) in isocratic mode (flow at $1 \mathrm{~mL} \mathrm{~min}^{-1}$ ), and detection was performed by fluorescence ( $\lambda$ excitation $=467 \mathrm{~nm}, \lambda$ emission $=525 \mathrm{~nm})$. The derivatization conditions for the determination of $\gamma$-glu-cys were the same previously described. Calibrations were carried out by using pure standards compounds solutions of GSH and $\gamma$-glu-cys. The analysis of the samples was made in duplicate.

\section{ORAC-FL assay}

The antioxidant capacity of IDY permeates and GSH was measured by ORAC-

210 fluorescein (ORAC-FL) assay based on that proposed previously ${ }^{24}$. Briefly, the reaction was carried out at $37^{\circ} \mathrm{C}$ in $75 \mathrm{mM}$ phosphate buffer $(\mathrm{pH}=7.4)$ and the final assay mixture $(200 \mathrm{uL})$ contained FL $(70 \mathrm{nM})$, AAPH $(12 \mathrm{mM})$, and antioxidant [Trolox (1-8 $\mathrm{uM)}$ or sample at different concentration]. The plate was automatically shaken before the first reading and the fluorescence was recorded every minute for 80 minutes. A polestar Galaxy plate reader (BMG Labtechnologies GmbH, Offemburg, Germany) with 485-P excitation and 520-P emission filters was used. The equipment was controlled by the Fluostar Galaxy Software (version 4.11-0) for fluorescence measurement. Black 96-microwell microplates (96F untreated, Nunc, Denamark) were used. AAPH and Trolox solutions were prepared daily and FL was diluted from a stock solution $(1.17 \mathrm{mM}$ in $75 \mathrm{mM}$ phosphate at $\mathrm{pH} 7.4$. Fluorescence measurements were normalised to the curve of the blank (no antioxidant). From the normalised curves, the area under the fluorescence decay curve (AUC). The regression equation between net AUC and antioxidant concentration was calculated and the slope of the equation was used to calculate the ORAC-FL value by using the Trolox curve obtained for each assay. Final ORAC-FL values were expressed as $\mu \mathrm{mol}$ of Trolox equivalent/mg dry 
permeate (for the $<3 \mathrm{kDa}$ permeates from $\mathrm{g}$-IDY and $\mathrm{n}$-IDY) and in $\mu \mathrm{mol}$ of Trolox equivalent/mg pure compound for commercial GSH.

\section{Total free amino acids and peptides}

229

230

231

Free amino acids and peptides in model wine were determined according to the protocols proposed by Doi and co-workers ${ }^{25}$. Free amino acids were determined by the reaction of ninhydrin/Cd with the free amino group by measuring the absorbance at 507 $\mathrm{nm}$ (method 5$)^{25}$. On the other hand, free amino acids plus peptides were determined by the reaction of the amino group with ninhydrin/Sn by measuring the absorbance at 570 nm (method 1) ${ }^{25}$. A DU 70 spectrophotometer from Beckman Coulter (Fullerton, CA, USA) was used. Quantification was carried out on the basis of the standard curve of leucine, and results were expressed as $\mathrm{mg} \mathrm{N} / \mathrm{L}$. All the model wine samples were analysed by duplicate.

\section{Analysis of amino acids by RP-HPLC-FL}

Amino acids were analysed in duplicate by reversed-phase HPLC using a liquid chromatograph described in section 2.5. Samples were submitted to automatic precolumn derivatization with o-phthaldehyde (OPA) in the presence of 2mercaptoethanol following the method described by Moreno-Arribas and collaborators 26. Separation was carried out on a Waters Nova Pack C18 (150x 3.9 mm i.d., 60 A, $4 \mu \mathrm{m})$ column and the same type of precolumn. Detection was performed by fluorescence $(\lambda$ excitation $=340 \mathrm{~nm}, \lambda$ emission $=425 \mathrm{~nm})$.

\section{Analysis of sulphur-containing metabolites by CE-MS}

CE analyses were carried out in a P/ACE $5500 \mathrm{CE}$ apparatus from Beckman Coulter. The CE system was coupled to a TOF MS instrument from Bruker Daltonics (Bremen, Germany) through an orthogonal ESI interface model G1607A from Agilent 
250 Technologies (Palo Alto, CA, USA). Electrical contact at the ESI needle tip was 251 established via a sheath liquid delivered by a 74900-00-05 Cole Palmer syringe pump 252 (Vernon Hills, IL, USA). The electrophoretic separation was carried out using an uncoated fused-silica capillary (50 $\mu \mathrm{m}$ internal diameter, $363 \mu \mathrm{m}$ outside diameter and $80 \mathrm{~cm}$ total length) from Composite Metal Services (Worcester, England). Before first use, the separation capillary was conditioned by rinsing with $1 \mathrm{M} \mathrm{NaOH}$ for $10 \mathrm{~min}$, followed by 20 min with water, both using pressurized $\mathrm{N}_{2}$ at $20 \mathrm{psi}$ (1380 mbar). After each run, the capillary was conditioned with water during $2 \mathrm{~min}$, followed by BGE during 4 min. Injections were made at the anodic end using $\mathrm{N}_{2}$ pressure at $0.5 \mathrm{psi}(34.5$ mbar) for $80 \mathrm{~s}$. The electrophoretic separation was achieved applying $+25 \mathrm{kV}$ at room temperature in a BGE composed of $3 \mathrm{M}$ formic acid. Electrical contact at the ESI needle tip was established via a sheath liquid based on isopropanol-water $(50: 50, \mathrm{v} / \mathrm{v})$ and delivered at a flow rate of $0.24 \mathrm{~mL} / \mathrm{min}$. The mass spectrometer operated in the positive ion mode. The nebulizer and drying gas conditions were 0.4 bar $\mathrm{N}_{2}$ and $4 \mathrm{~L} / \mathrm{min} \mathrm{N}_{2}$, respectively, and maintaining the ESI chamber temperature at $250^{\circ} \mathrm{C}$. Spectra were acquired in the $50-700 \mathrm{~m} / \mathrm{z}$ range every $90 \mathrm{~ms}$. External and internal calibration of the TOF MS instrument was performed by introducing a $10 \mathrm{mM}$ sodium formate solution through the separation capillary. The ions used for the calibration of the TOF MS instrument were next: 90.9766, 158.9641, 226.9515, 294.9389, 362.9263, 430.9138, 498.9012 and $566.8886 \mathrm{~m} / \mathrm{z}$. TOF MS provided a high mass resolution and high mass accuracy with errors usually below $10 \mathrm{ppm}$. Selected mass spectra were processed through the software DataAnalysis (Bruker Daltonics), which provided a list of possible elemental formulas by using the Generate-Molecular Formula Editor (Bruker Daltonics), which provided standard functionalities such as minimum/maximum elemental range, electron configuration and ring-plus double bonds equivalents, as well 
as a comparison between the theoretical and the experimental isotopic pattern (SigmaValue $^{\mathrm{TM}}$ ) for increased confidence in the theoretical molecular formula assignment.

\section{Non-targeted metabolomic analysis by FT-ICR MS}

FT-ICR MS was used to obtain ultra-high resolution $(>100,000)$ mass spectra. Separation and identification of the metabolites was possible without the need of chromatography or derivatisation due to the ultra-high mass accuracy. Commercially beer maltooligosaccharides were used as mass calibrants and tunning standards in both the positive and negative ion modes ${ }^{27}$. The maximum mass error achieved was below 2 ppm.

Experiments were performed on a hybrid triple quadruple-FT-ICR instrument Varian $920 \mathrm{MS}$ provided with a 7.0 T actively shielded superconducting magnet and equipped with an electrospray ionization (ESI) source. The conditions in the electrospray were next: in positive mode the potential in the needle was set at $4.5 \mathrm{kV}$ and $600 \mathrm{~V}$ in the shield. The capillary potential to pass the ions from the source to the skimmer was set in a range between 40 and $60 \mathrm{~V}$. Nitrogen was employed as nebulizer gas and its pressure was 50 psi. The pressure for drying gas was set at $18 \mathrm{psi}$ and the temperature at $300{ }^{\circ} \mathrm{C}$. The flow rate of the sample was kept at $15 \mu \mathrm{L} / \mathrm{min}$ and injected by direct infusion. In the negative mode MS parameters were next: $-3.5 \mathrm{kV}, 600 \mathrm{~V}$, from -70 to $-90 \mathrm{~V}$ in the capillary, 18 psi and $300{ }^{\circ} \mathrm{C}$. Sample flow rate was $15 \mu \mathrm{L} / \mathrm{min}$. Air was used instead of nitrogen as nebulizer gas. The spectra were acquired in full scan mode and defining a mass range from 100 to 1000 of m/z. The internal detection signal in the cell detector of the FT-ICR was optimized for a mass of $500 \mathrm{~m} / \mathrm{z}$. 
Monoisotopic mass and isotope clusters profiles were extracted from the raw data by using Varian MS Peak Hunter software version 4.1.89. These two parameters were used by the same software to get the elemental composition following the next criteria: error was set at $2 \mathrm{ppm}$ and only chemical formulas containing $\mathrm{C}, \mathrm{H}, \mathrm{N}, \mathrm{O}, \mathrm{P}$ and $\mathrm{S}$ were allowed. The spectra were exported to mzXML format and applied against XCMS ${ }^{28}$ online METLIN database. When the results from the METLIN database were in good agreement in accordance with the chemical formula found in Varian MS Peak Hunter, the metabolite was given as a good result.

\section{Statistical analysis}

Data from the analysis of aroma compounds (RPAs) from the model wine experiments were submitted to one-way ANOVA analysis and LSD to test the effect of wine treatment.

\section{RESULTS AND DISCUSSION}

Effect of the addition of GSH and the $<3 \mathrm{kDa}$ permeates isolated from IDYs on specific wine terpenes in model wines under accelerated aging conditions

To determine the effect of GSH-enriched IDY preparations on the evolution of aroma compounds during aging, and wether the GSH released from IDYs into the wines might have a role on the behaviour of aroma compounds during aging, the $<3 \mathrm{kDa}$ permeate from a g-IDY preparation was isolated by ultracentrifugation and spiked into model wines, as described in section 2.1. Model wines spiked with this permeate were coded as g-IDY-W. Ultrafiltration ensured the removal of glycoproteins (with higher molecular weights than $3 \mathrm{kDa}$ ) from the IDY preparations that might interact with volatiles ${ }^{21,22}$, masking the potential action of GSH on the aroma compounds, which was the main objective of this study. In addition, to compare the effect of a different 
type of IDY preparation currently commercialized as a fermentation nutrient (without any claim on wine aroma protection), the $<3 \mathrm{kDa}$ permeate was also isolated and added to model wines (n-IDY-W). In addition, two other types of model wines added with commercial GSH (10 mg/L) referred to glut-W and control model wines, without any addition, (cont-W) ), were also prepared. To avoid chemical transformations due to the high reactivity of terpene compounds ${ }^{3}$, each model wine solution was individually aromatised with a single aroma compound (nerol, $\beta$-citronellol, $\alpha$-terpineol and linalool). These aromas were selected because they are characteristic of young wines providing pleasant floral-fruity nuances and are very sensitive to the oxidation phenomena $^{3,29,30}$. The behaviour of the four terpene compounds was evaluated in all the model wines at the beginning of the experiment $(\mathrm{t}=0 \mathrm{~d})$, corresponding to non-oxidised model wines and after three weeks of accelerated aging conditions $(t=21 d)$. Figure 1 shows the percentage of decrease in relative peak area (RPA) between the initial wine sample (non-oxidised) and the wines after 21 days of aging for each aroma compound and wine type. As it can be seen, there was a general decrease in RPAs for all the aromas during aging, which ranged from 24 to $45 \%$, therefore, confirming the outstanding effect of aging on the loss produced in these types of aroma compounds 2,3 , ${ }^{14}$, which can be attributable to oxidation phenomena ${ }^{3,29,30}$. Interestingly, compared to the control wine solution, $\alpha$-terpineol and linalool showed a lower reduction in RPAs in the model wines supplemented with the $<3 \mathrm{k}$ Da permeate isolated from either of both preparations (g-IDY or n-IDY). In the case of nerol, a slightly lower reduction in RPAs was also observed in the g-IDY model wine, although this effect was not statistically significant. $\beta$-Citronellol did not show a significant effect either. These results seemed to indicate a protective effect of these preparations on some specific aroma compounds, which is in agreement with the aroma sensory differences recently found between 
control rosé wines (without IDY added) and rosé wines produced in cellar conditions with the same type of g-IDY after 9 months of aging ${ }^{20}$.

However, the addition of commercial GSH to the model wine solutions did not have a significant effect under the essayed conditions. Different published works have shown an inhibition of the decline of certain aroma compounds when using GSH at a similar or even lower dosage in wines or model wine systems ${ }^{4,6-9}$. Nonetheless, it is well known that the main effect of GSH in wines, is its ability to react with orthoquinones produced by oxidation of caftaric acid (and other polyphenols) to give GRP (grape reaction product) by action of polyphenols oxidases blocking the following steps in which polyphenols are involved (polymerization) and responsible for browning 4, 6, 17 . Moreover, orthodiphenols can be directly oxidized in the presence of oxygen and some cations (iron, copper) to orthoquinones and hydrogen peroxide, which might be involved in subsequent aroma oxidation ${ }^{4}$. In our experimental conditions this action mechanism was limited because of the absence of polyphenols to react with GSH in the model wine, which seems to explain the absence of a noticeable effect of GSH on aroma protection in the model wines supplemented with commercial GSH. However, GSH presents scavenging hydroperoxyde and hydroxyl radicals properties, which might have allowed it to act as antioxidant by other mechanisms different than its capacity to interact with ortoquinones in polyphenol free systems ${ }^{10,11}$. Nonetheless, on the basis of our results, this mechanism did not seem as significant in our experimental conditions. In spite of this, it is important highlight that this model system allowed us to uncover the potential role of other yeast components, different to GSH and contained in the $<3 \mathrm{kDa}$ fraction, which seemed to be related to the protection of some terpenes in model wines submitted to accelerated aging conditions. 
371 Following this rationale, to find out if the observed reduction in peak areas for some of

372 the terpenes employed in our study was effectively related to an antioxidant effect 373 exerted by the IDY permeates, the radical scavenging activity of both of them was 374 calculated by using the ORAC-FL method. The ORAC values were 0.33 and $0.22 \mu$ mol 375 TE/ mg dry permeate for g-IDY and n-IDY permeates respectively, showing that the 376 two permeates had a positive and a similar antioxidant capacity. These results are in agreement with the previous experiment, in which g-IDY-W and n-IDY-W wines showed a similar reduction in the corresponding peak areas for the same aroma compounds (linalool and $\alpha$-terpineol). In addition, to confirm the antioxidant activity of the commercial GSH employed in this experiment, the ORAC value for the pure compound was also calculated, this is $10.7 \mu \mathrm{mol} \mathrm{TE} / \mathrm{mg}$ pure compound, thus, corroborating its high antioxidant capacity, comparable to other important wine antioxidants such as polyphenols. As an example, for a representative set of pure polyphenolic compounds, the calculated ORAC values ranged between 2.35 and 18.16 $\mu \mathrm{mol}$ TE/mg pure compound determined for myricetin and caffeic acid respectively ${ }^{31}$. Nevertheless, and as previously stated, in spite of the high antioxidant activity determined for GSH, this compound did not exert a noticeable effect in preventing aroma oxidation in a model wine in the absence of polyphenols, as used in the present work. However, these results confirmed the antioxidant properties of both IDY permeates in agreement with the better preservation of some terpenes observed in the model wines supplemented with them. However, this effect, at least in the g-IDY wines, might have been a consequence of the higher amount of GSH contained in the g-IDY permeate compared to that added into the wines by using commercial GSH $(10 \mathrm{mg} / \mathrm{L})$, 
lower aroma loss in g-IDY wines. Therefore, a quantitative determination of GSH, total

396 GSH, and the precursor $\gamma$-glutamylcysteine, was carried out.

\section{Determination of GSH, total GSH, and $\gamma$-glutamylcysteine}

Reduced GSH, total GSH and the precursor $\gamma$-glutamyl-cysteine were analysed by using a previously optimised RP-HPL-FL method ${ }^{18}$. These results are shown in Table 1. As

400 it can be seen, only the g-IDY permeate presented detectable levels of GSH (1293 $\mathrm{mg} / \mathrm{L})$ and $\gamma$-glutamyl-cysteine (873 mg/L). The amount of total GSH was higher $(3147$ $\mathrm{mg} / \mathrm{L}$ ), meaning that only $41 \%$ of glutathione was in its reduced form (GSH) and available to act as a potential antioxidant. However, in the n-IDY permeate, there were traces of GSH or GSH related compounds. This is in agreement with some previously published works in which in a screening of commercial oenological IDY preparations, only those claimed to be GSH-enriched IDY preparations released reduced GSH into synthetic wines ${ }^{18}$. Taking into consideration the added amount of each permeate into the model wines $(100 \mu \mathrm{L})$, the final amount of reduced and total GSH in g-IDY-W model wines was $2.6 \mathrm{mg} / \mathrm{L}$ and $6.3 \mathrm{mg} / \mathrm{L}$ respectively, which is very close to the amounts determined in model wines when using IDYs at the recommended wine dosage (0.3 $\mathrm{g} \mathrm{IDYs/L),} \mathrm{which} \mathrm{has} \mathrm{been} \mathrm{established} \mathrm{to} \mathrm{be} \mathrm{between} 1$ and $\left.2.5 \mathrm{mg} / \mathrm{L}^{18,}{ }^{19}\right)$. Considering that no GSH (or other GSH related compounds) were detected in n-IDY-W model wine and that the amount of GSH determined in g-IDY-W was lower than the amount of commercial GSH employed in the GSH-W model wine $(10 \mathrm{mg} / \mathrm{L})$, it could be concluded that the observed antioxidant effect of these preparations on the reduction of aroma loss during wine aging did not seem to be linked to the sole antioxidant action of GSH but could be due to other compounds or to the combined action of GSH and other antioxidant compounds from yeast origin present in the permeates (at least in n- 
419 IDY-W model wine). In trying to elucidate these compounds, a comprehensive 420 chemical characterization of both g-IDY and n-IDY permeates was carried out.

\section{Analysis of other sulphur-containing compounds by CE-MS}

422 In addition to GSH, other biological sulphur-containing compounds have been said to 423 present antioxidant properties ${ }^{32}$. Thus, the analysis of other low molecular weight 424 sulphur-containing compounds in the $<3 \mathrm{kDa}$ permeates from both g-IDY and n-IDY samples was performed by using CE-MS. This targeted analysis was carried out on the basis of the presence of at least one $\mathrm{S}$ atom in the molecular structure. The existence of sulphur in the molecule requires the presence in the mass spectra of an isotopic peak 2 Da higher than the molecular ion and at least $4 \%$ in intensity per sulphur. After further inspection of n-IDY and g-IDY CE-MS profiles, besides the two sulphur containing amino acids methionine and cysteine, another 14 high abundant sulphur-containing compounds were found in the permeate from g-IDY sample. In Figure 2, extracted ion electropherograms (EIEs) from these two amino acids and the most abundant sulphurcontaining compounds are represented (continuous and dotted lines for g-IDY and nIDY samples, respectively). The electropherogram from n-IDY showed, however, only three major peaks (compounds 1,3 and 5) and methionine and cysteine were not detected either. Detailed information about the identity of these compounds is shown in

Table 2. As it can be seen in this table, eight out of fourteen compounds could be tentatively identified. Most of them corresponded to glutathione derivatives (compounds 7, 8, 10, 11 and 14) and in general, the rest of the identified compounds were compounds related to the amino acids cysteine and methionine. Many sulphur compounds, including the sulphur containing amino acids, have been shown to exhibit antioxidant properties in vivo and in vitro ${ }^{32,33}$ and all of them are synthesised from methionine ${ }^{33} 29$. Therefore, the absence of this amino acid in the n-IDY permeate is in 
agreement with the lack of sulphur-containing compounds in this sample. In synthetic wines, Papadopoulou and Roussis ${ }^{8}$ showed that some sulphur-containing compounds, such as $\mathrm{N}$-acetylcysteine are effective at decreasing the rate of reduction of some aroma compounds (including terpenes) during wine aging. On the basis of existent literature and on the chemical structure of the sulphur-containing compounds identified in g-IDY, the involvement of these compounds in the antioxidant activity determined in the model wines spiked with the g-IDY permeate seems plausible. However, the absence of sulphur-containing compounds in the n-IDY permeate might indicate that the antioxidant effect determined in n-IDY-W model wines should be due to compounds from a different nature.

\section{Analysis of nitrogen-containing compounds}

Previous works have already shown that free amino acids represent the greatest nitrogen fraction released by IDYs into model wines whose specific composition depends on the type of IDYs ${ }^{22}$. In addition, the antioxidant effect exerted by different types of nitrogen compounds such as peptides and amino acids (other than sulphur-containing amino acids) have also been described ${ }^{34,35}$. Therefore, in order to determine which other chemicals might be responsible for the antioxidant effect found in both permeates, their nitrogen composition was determined. Table 3 shows the content of total free amino acids, free amino acids and peptides, and individual amino acids determined by RPHPLC-FL. As it can be seen, both permeates exhibited important qualitative and quantitative differences. Firstly, the content of free amino acids was clearly higher in the g-IDY permeate (2964 $\mathrm{mg} \mathrm{N} / \mathrm{L})$ than in the $\mathrm{n}$-IDY permeate $(1248 \mathrm{mg} \mathrm{N} / \mathrm{L})$. However, n-IDY permeate was richer in $\mathrm{N}$ from peptides. Besides, the amino acid profile showed important differences between IDYs. For instance, the major amino acids in g-IDY permeate were glutamic acid $(62.2 \mathrm{mg} / \mathrm{L})$, threonine $(56.27 \mathrm{mg} / \mathrm{L})$ and 
$\beta$-alanine (45.82 mg/L), whilst histidine (56.39 mg/L), glycine $(33.15 \mathrm{mg} / \mathrm{L})$, and lysine

$470(21.99 \mathrm{mg} / \mathrm{L})$ were most abundant in the permeate from n-IDY. Some amino acids have

471 been associated to relatively important radical scavenging activities in the order

472 tryptophan $>$ tyrosine $>$ methionine $>$ cysteine $>$ phenylalanine ${ }^{34}$. In this sense, only

473 tyrosine was detected in the free form in both permeates, although in a relatively low

474 concentration (5.6 and $1.05 \mathrm{mg} / \mathrm{L}$ for $\mathrm{g}$-IDY and $\mathrm{n}$-IDY permeates, respectively), whereas phenylalanine and tryptophan were not detected in any of the samples.

476 Corroborating the previous results obtained by CE-MS, methionine was only identified in the g-IDY permeate $(1.55 \mathrm{mg} / \mathrm{L})$. However, the analytical method employed did not allow the detection of cysteine, although its sole presence in the g-IDY permeate was previously confirmed by CE-MS analysis. Therefore, considering the amino acidic profile, the contribution of free amino acids to the total antioxidant activity of g-IDY and n-IDY permeates did not seem very relevant, meaning that there were still other compounds which should be more related to this activity.

\section{Non-targeted metabolomic ESI FT-ICR MS analysis}

Direct infusion ESI-FT-ICR-MS was further employed to gain insight on the chemical metabolites responsible for the antioxidant effect exerted by the two permeates. This technique has been proposed as one of the best techniques to directly investigate complex natural mixtures ${ }^{36}$ due to the high mass resolving power and mass accuracy. It has also been recently applied to food materials such as coffee ${ }^{37}$ and other metabolomic studies of natural products ${ }^{38}$.

Figures 3a and 3b show the ESI-FT-ICR-MS spectra from g-IDY and n-IDY permeates respectively. Although they were acquired in the positive and negative ion mode, figure

4923 only depicts the MS from the positive mode. Visually, it is possible to see, that both 
MS profiles were substantial different. This is in good agreement with the more through ion identification study that was performed and summarized in Table 4. Using positive and negative ionization modes it was possible to tentatively identify a total of 10 compounds, in which eight of them were detected in the g-IDY permeate and only four, in the n-IDY permeate. Some of the identified compounds were sulphur containing compounds, such as S-glutathionyl-L-cyteine, $\gamma$-glutamyl-cystine and oxidized glutathione which were already identified by CE-MS in the g-IDY sample. In addition, the ion $556.1379 \mathrm{~m} / \mathrm{z}$ was identified as a biotinil-5-AMP, an intermediary in the synthesis of biotine ${ }^{39}$. This compound was already detected but not identified by CEMS in the g-IDY permeate. In any case, in agreement with the results obtained from other analytical techniques (HPLC-FL, CE-MS), there were non sulphur-containing compounds in n-IDY permeate. However, a very interesting finding was the detection in both samples of some small peptides, specifically tripeptides. Two of them, were found in both permeates and were tentatively identified as Histidine/Cysteine/Lysine and a Methionine/Lysine/Histidine containing peptides. Their MS and chemical structures are shown in figure 4. Because of their low concentration in the sample it was not possible to confirm their sequence. Even more interestingly, was the finding of another two peptides only in n-IDY permeate containing Methionine/Aspartic/Triptophane and Tyrosine/Histidine/Methionine (Figure 4). It is worth mentioning that the antioxidant properties of small peptides, mainly contained in fermented food, have been extensively documented ${ }^{35}$. As it was previously commented, small peptides containing tryptophan, tyrosine, methionine, cysteine and phenylalanine have been described to exhibit a high antioxidant activity ${ }^{34}$. In the present study, from the two peptides detected in the permeates from g-IDY and n-IDY, only one (histidine/cysteine/lysine) had an amino acid (cysteine) which could be involved in the antioxidant properties. However, the two 
518 peptides exclusively identified in the n-IDY permeate (methionine/aspartic 519 acid/tryptophane and tyrosine/histidine/methionine), contained two of these amino acids 520 each. Even more, both peptides contained tryptophan and tyrosine, the two highest 521 antioxidant amino acids. Previously published works have already described the 522 biological activities (antioxidant, antihypertensive) of peptides from yeast origin found 523 in synthetic wines submitted to autolytic conditions ${ }^{40}$ and in red wines ${ }^{41,42}$, although 524 their chemical structure remained unresolved. Moreover, considering these results, the 525 preservation of aroma and reduction of aroma loss in wines aged on lees that has been 526 linked to the GSH released by yeast autolysis ${ }^{6}$ might also be attributable to other types 527 of small peptides, which could have even higher antioxidant properties than GSH.

528 In conclusion, it has been proven that the use of IDY preparations (with or without 529 GSH) reduce the loss of certain terpenes during the accelerated aging of model wines. It 530 has also been shown that g-IDY preparations do in fact contain GSH in its reduced state 531 which can contribute to the aroma preservation in model wines, but they also contain other sulphur compounds of yeast origin that might also act as antioxidants. In addition, both g-IDY and n-IDY contained small peptides (tripeptides) with methionine, 534 tryptophan and tyrosine, which seem to be involved in the antioxidant properties 535 determined in the permeates isolated from both IDYs also being effective in the 536 preservation of some terpenes during model wine aging. Taking into consideration the 537 instability of GSH in wines (easily oxidized, fast combination with polyphenols, etc), 538 this finding could be of technological interest assuming the higher stability of these 539 antioxidant peptides when used for example, after wine bottling. The oncoming work 540 will be directed to unequivocally identify the sequence of these compounds and further 541 studies are needed to confirm the antioxidant effect of these peptides in closer 542 winemaking conditions. Undoubtedly, this will be interesting for the wine and 
543 biotechnological industry in order to redirect the formulation of IDY preparations to

544 achieve specific and effective winemaking applications.

\section{ACKNOWLEDGEMENTS}

546 Authors thank Dr. Hernández-Ledesma for her valuable assistance during the ORAC-

547 FL analysis.

548 


\section{LITERATURE CITED}

550 (1) Escudero, A.; Asensio, E.; Cacho, J.; Ferreira, V., Sensory and chemical changes of young white wines stored under oxygen. An assessment of the role played by

(5) Pozo-Bayon, M. A.; Monagas, M.; Bartolome, B.; Moreno-Arribas, M. A., Wine Features Related to Safety and Consumer Health: An Integrated Perspective. Crit. Rev. Food Sci. 2012, 52, 31-54.

(6) Dubourdieu, D.; Lavigne-Cruège, V., The role of glutathione on the aromatic evolution of dry white wine. Vinidea.net 2004, 02.

(7) Papadopoulou, D.; Roussis, I. G., Inhibition of the decline of linalool and alphaterpineol in muscat wines by glutathione and n-acetyl-cysteine. Ital J. Food Sci. 2001, 13, 413-419.

(8) Papadopoulou, D.; Roussis, I. G., Inhibition of the decrease of volatile esters and terpenes during storage of a white wine and a model wine medium by glutathione and N-acetylcysteine. Int. J. Food Sci. 2008, 43, 1053-1057.

(9) Roussis, I. G.; Lambropoulus, I. G.; Tzimas, P., Protection of volatiles in a wine with low sulfur dioxide by caffeic acid or glutathione. Am. J. Enol. Vitic. 2007, $58,274-278$.

(10) Fahey, R. C.; Sundquist, A. R., EVOLUTION OF GLUTATHIONE METABOLISM. Advances in Enzymology and Related Areas of Molecular Biology 1991, 64, 1-53.

(11) Field, J. A.; Thurman, E. M., Glutathione conjugation and contaminant transformation. Environmental Science \& Technology 1996, 30, 1413-1418.

(12) Penninckx, M., A short review on the role of glutathione in the response of yeasts to nutritional, environmental, and oxidative stresses. Enzyme Microb. Tech. 2000, 26, 737-742. 
(13) Penninckx, M. J., An overview on glutathione in Saccharomyces versus nonconventional yeasts. Fems Yeast Res. 2002, 2, 295-305.

(14) Roussis, I. G.; Lambropoulos, I.; Papadopoulou, D., Inhibition of the decline of volatile esters and terpenols during oxidative storage of Muscat-white and Xinomavro-red wine by caffeic acid and N-acetyl-cysteine. Food Chem. 2005, 93, 485-492.

(15) Roussis, I. G.; Sergianitis, S., Protection of some aroma volatiles in a model wine medium by sulphur dioxide and mixtures of glutathione with caffeic acid or gallic acid. Flavour Frag. J. 2008, 23, 35-39.

(16) Pozo-Bayon, M. A.; Andujar-Ortiz, I.; Moreno-Arribas, M. A., Scientific evidences beyond the application of inactive dry yeast preparations in winemaking. Food Res. Int, 2009, 42, 754-761.

(17) Kritzinger, E. C.; Bauer, F. F.; Toit, W. J. d., Role of glutathione in winemaking: a review. J. Agric. Food Sci. 2013, 61, 269-277.

(18) Andujar-Ortiz, I.; Angeles Pozo-Bayon, M.; Victoria Moreno-Arribas, M.; Martin-Alvarez, P. J.; Rodriguez-Bencomo, J. J., Reversed-Phase HighPerformance Liquid Chromatography-Fluorescence Detection for the Analysis of Glutathione and Its Precursor gamma-Glutamyl Cysteine in Wines and Model Wines Supplemented with Oenological Inactive Dry Yeast Preparations. Food Anal Method 2012, 5, 154-161.

(19) Kritzinger, E. C.; Stander, M. A.; Du Toit, W. J., Assessment of glutathione levels in model solution and grape ferments supplemented with glutathioneenriched inactive dry yeast preparations using a novel UPLC-MS/MS method. Food Addit. Contam A. 2013, 30, 80-92.

(20) Andújar-Ortiz, I.; C., C.; Martín-Álvarez, P. J.; Moreno-Arribas, M. A.; PozoBayón, M. A., Impact of using new commercial gluthatione enriched inactive dry yeast oenological preparations on the aroma and sensory properties of wines. Int. J. Food Prop. on-line version (3 Aug 2013) 2013. DOI: 10.1080/10942912.2012.685682

(21) Comuzzo, P.; Tat, L.; Tonizzo, A.; Battistutta, F., Yeast derivatives (extracts and autolysates) in winemaking: Release of volatile compounds and effects on wine aroma volatility. Food Chem. 2006, 99, 217-230.

(22) Pozo-Bayon, M. A.; Andujar-Ortiz, I.; Alcaide-Hidalgo, J. M.; Martin-Alvarez, P. J.; Moreno-Arribas, M. V., Characterization of Commercial Inactive Dry Yeast Preparations for Enological Use Based on Their Ability To Release Soluble Compounds and Their Behavior toward Aroma Compounds in Model Wines. J. Agric. Food Sci. 2009, 57, 10784-10792.

(23) Rodríguez-Bencomo, J. J.; Muñoz-Gonzalez, C.; Andujar-Ortiz, I.; MartinAlvarez, P. J.; Moreno-Arribas, M. V.; Pozo-Bayon, M. A., Assessment of the effect of the non-volatile wine matrix on the volatility of typical wine aroma 
compounds by headspace solid phase microextraction/gas chromatography analysis. J. Sci. Food Agric. 2011, 91, 2484-2494.

(24) Davalos, A.; Gomez-Cordoves, C.; Bartolome, B., Extending applicability of the oxygen radical absorbance capacity (ORAC-fluorescein) assay. J. Agric. Food Sci. 2004, 52, 48-54.

(25) Doi, E.; Shibata, D.; Matoba, T., MODIFIED COLORIMETRIC NINHYDRIN METHODS FOR PEPTIDASE ASSAY. Anal. Biochem. 1981, 118, 173-184.

(26) Moreno-Arribas, M. V.; Bartolome, B.; Pueyo, E.; Polo, M. C., Isolation and characterization of individual peptides from wine. J. Agric. Food Sci. 1998, 46, 3422-3425.

(27) Clowers, B. H.; Dodds, E. D.; Seipert, R. R.; Lebrilla, C. B., Dual polarity accurate mass calibration for electrospray ionization and matrix-assisted laser desorption/ionization mass spectrometry using maltooligosaccharides. Anal. Biochem. 2008, 381, 205-213.

(28) Tautenhahn, R.; Patti, G. J.; Rinehart, D.; Siuzdak, G., XCMS Online: A WebBased Platform to Process Untargeted Metabolomic Data. Anal. Chem. 2012, 84, 5035-5039.

(29) Batiashvili, T. A.; Bezzubov, A. A.; Chichashvili, N. D.; Rodopulo, A. K., Changes in essential-oil composition of grapes during their processing. Applied Biochemistry and Microbiology 1981, 16, 450-452.

(30) Neuenschwander, U.; Guignard, F.; Hermans, I., Mechanism of the Aerobic Oxidation of alpha-Pinene. Chemsuschem 2010, 3, 75-84.

(31) Villano, D.; Fernandez-Pachon, M. S.; Troncoso, A. M.; Garcia-Parrilla, M. C., Comparison of antioxidant activity of wine phenolic compounds and metabolites in vitro. Anal. Chim. Acta 2005, 538, 391-398.

(32) Battin, E. E.; Brumaghim, J. L., Antioxidant Activity of Sulfur and Selenium: A Review of Reactive Oxygen Species Scavenging, Glutathione Peroxidase, and Metal-Binding Antioxidant Mechanisms. Cell Biochem. Biophys. 2009, 55, 1-23.

(33) Parcell, S., Sulfur in human nutrition and applications in medicine. Altern. Med. Rev. 2002, 7, 22-44.

(34) Hernandez-Ledesma, B.; Davalos, A.; Bartolome, B.; Amigo, L., Preparation of antioxidant enzymatic hydrolysates from (alpha-lactalbumin and betalactoglobulin. Identification of active peptides by HPLC-MS/MS. J. Agric. Food Sci. 2005, 53, 588-593.

(35) Samaranayaka, A. G. P.; Li-Chan, E. C. Y., Food-derived peptidic antioxidants: A review of their production, assessment, and potential applications. $J$. Funct.Food 2011, 3, 229-254. 
(36) Brown, S. C.; Kruppa, G.; Dasseux, J. L., Metabolomics applications of FT-ICR mass spectrometry. Mass Spect. Rev. 2005, 24, 223-231.

(37) Garrett, R.; Vaz, B. G.; Hovell, A. M. C.; Eberlin, M. N.; Rezende, C. M., Arabica and Robusta Coffees: Identification of Major Polar Compounds and Quantification of Blends by Direct-Infusion Electrospray Ionization-Mass Spectrometry. J. Agric. Food Sci. 2012, 60, 4253-4258.

(38) Feng, X.; Siegel, M. M., FTICR-MS applications for the structure determination of natural products. Anal. Bioanal. Chem. 2007, 389, 1341-1363.

(39) Rodríguez-Melendez, R., Importancia del metabolismo de la biotina. La Revista de Investigación Clínica 2000, 52, 194-199.

(40) Alcaide-Hidalgo, J. M.; Pueyo, E.; Polo, M. C.; Martinez-Rodriguez, A. J., Bioactive peptides released from Saccharomyces cerevisiae under accelerated autolysis in a wine model system. J. Food Sci. 2007, 72, M276-M279.

(41) Pozo-Bayon, M. A.; Alcaide, J. M.; Polo, M. C.; Pueyo, E., Angiotensin Iconverting enzyme inhibitory compounds in white and red wines. Food Chem. 2007, 100, 43-47.

(42) Takayanagi, T.; Yokotsuka, K., Angiotensin I converting enzyme-inhibitory peptides from wine. Am. J. Enol. Vitic. 1999, 50, 65-68.

\section{FUNDING SOURCES}

This work was funded by the MINECO (AGL2012-04172-C02-01, and CONSOLIDER INGENIO 2010 (FUN-C-FOOD, CSD2007-063, Projects), and by Agrovín, S.A. (I+D 20132446 Contract). J.J Rodríguez-Bencomo thanks CSIC for the JAE-doc contract. 


\section{FIGURE CAPTIONS:}

728 Figure 1. Percentage of decrease in the relative peak area of the aroma compounds in 729 the model wines submitted to accelerated aging conditions (wines supplemented with 730 the $<3 \mathrm{kDa}$ permeates isolated from $\mathrm{g}$-IDY and $\mathrm{n}$-IDY, wines added with $10 \mathrm{mg} / \mathrm{L} \mathrm{of}$ 731 commercial glutathione and control wines without any treatment) compared to the 732 original model wines (0 days). Results of ANOVA and LSD test are indicated with 733 different letters (a-c). ns: no significant differences

734 Figure 2. CE-TOF-MS extracted ion electropherograms (EIEs) of (A) the 14 most 735 abundant sulphur-containing compounds, and (B) methionine and cysteine from g-IDY 736 and n-IDY samples. Continuous line for $\mathrm{g}$-IDY permeate and dotted line for $\mathrm{n}$-IDY 737 permeate, are used. See Section 2.9 for experimental conditions.

738 Figure 3. ESI (+) FT-ICR MS of the $<3 \mathrm{kDa}$ permeate from g-IDY (a) and n-IDY (b) 739 samples.

740 Figure 4. Chemical structures and EI-FT-ICR MS corresponding to the peptides 741 identified in the $<3 \mathrm{kDa}$ permeates from g-IDY and n-IDY. (Met/Asp/Trp and Tyr His 742 Met) were only identified in the permeate from n-IDY 
TABLES:

745 Table 1. Concentration of total GSH, reduced GSH and $\gamma$-Glutamyl-cysteine

746 determined in the $<3 \mathrm{kDa}$ permeates isolated from $\mathrm{g}$-IDY and $\mathrm{n}$-IDY preparations

\begin{tabular}{cccc}
\hline $\begin{array}{c}\text { IDY } \\
\text { preparation }\end{array}$ & $\begin{array}{c}\text { Total GSH } \\
(\mathrm{mg} / \mathrm{L})\end{array}$ & $\begin{array}{c}\text { Reduce GSH } \\
(\mathrm{mg} / \mathrm{L})\end{array}$ & $\begin{array}{c}\gamma \text {-Glutamyl-cysteine } \\
(\mathrm{mg} / \mathrm{L})\end{array}$ \\
\hline g-IDY & $3147 \pm 118$ & $1293 \pm 76$ & $873 \pm 63$ \\
n-IDY & n.d. & n.d. & n.d. \\
\hline
\end{tabular}

747

748 
Table 2. Tentative identification of sulphur-containing compounds found in the $<3 \mathrm{kDa}$ permeates isolated from g-IDY and n-IDY preparations after CE-MS analysis.

\begin{tabular}{|c|c|c|c|c|c|c|c|c|c|}
\hline Compound & $\begin{array}{l}\text { Time } \\
(\min )\end{array}$ & $\begin{array}{c}\text { Peak area } \\
\text { (g-IDY) }\end{array}$ & $\begin{array}{c}\text { Peak area } \\
\text { (n-IDY) }\end{array}$ & $\mathrm{m} / \mathrm{z}(\exp )$ & m/z (thr) & $\begin{array}{l}\text { Error } \\
(\mathrm{ppm})\end{array}$ & Formula & Tentative ID & HMDB $*$ code \\
\hline 1 & 12.03 & 1489462 & 204104 & 385.1318 & 385.1289 & 7.6 & $\mathrm{C}_{14} \mathrm{H}_{20} \mathrm{~N}_{6} \mathrm{O}_{5} \mathrm{~S}$ & S-Adenosylhomocysteine & HMDB00939 \\
\hline 2 & 12.45 & 2807046 & $\mathrm{ND}^{*}$ & 371.1182 & & & & $\mathrm{NF}^{*}$ & \\
\hline 3 & 12.68 & 3650062 & 782426 & 223.0792 & & & & NF & \\
\hline 4 & 12.75 & 1427597 & ND & 237.091 & 237.09034 & -2.7 & $\mathrm{C} 8 \mathrm{H} 16 \mathrm{~N} 2 \mathrm{O} 4 \mathrm{~S}$ & $\begin{array}{c}\text { Methionyl-Serine, } \\
\text { Serinyl-Methionine, } \\
\text { S-aminomethyldihydrolipoamide }\end{array}$ & $\begin{array}{l}\text { HMDB29045, } \\
\text { HMDB29045, } \\
\text { HMDB06239 }\end{array}$ \\
\hline 5 & 14.49 & 891150 & 740927 & 298.1011 & 298.0968 & -14.3 & C11H15N5O3S & 5'-Methylthioadenosine & HMDB01173 \\
\hline 6 & 14.87 & 2142027 & ND & 370.0768 & & & & NF & \\
\hline 7 & 15.41 & 2245896 & ND & 427.0974 & 427.0952 & -5.2 & $\mathrm{C} 13 \mathrm{H} 22 \mathrm{~N} 4 \mathrm{O} 8 \mathrm{~S} 2$ & S-Glutathionyl-L-Cysteine & HMDB00656 \\
\hline 8 & 15.74 & 3898205 & ND & 499.1182 & $\begin{array}{c}499.11631 \\
1\end{array}$ & -3.8 & $\mathrm{C} 16 \mathrm{H} 26 \mathrm{~N} 4 \mathrm{O} 10 \mathrm{~S} 2$ & N,N'-Bis ( $\gamma$-glutamyl)cystine & HMDB38458 \\
\hline 9 & 16.18 & 7992966 & ND & 556.1404 & 278.5817 & & & $\mathrm{NF}$ & \\
\hline 10 & 16.55 & 6240395 & ND & $\begin{array}{c}613.16 \\
307.0921\end{array}$ & 613.1592 & -2.5 & C20H32N6O12S2 & Oxidized glutathione & HMDB03337 \\
\hline 11 & 17.43 & 5710438 & ND & 251.0716 & 251.0696 & -7.9 & $\mathrm{C} 8 \mathrm{H} 14 \mathrm{~N} 2 \mathrm{O} 5 \mathrm{~S}$ & $\gamma$-Glutamylcysteine & HMDB01049 \\
\hline 12 & 17.9 & 369996 & ND & 454.096 & & & & $\mathrm{NF}$ & \\
\hline 13 & 17.98 & 2125131 & ND & 148.0446 & & & & NF & \\
\hline 14 & 18.37 & 6861257 & ND & 308.0952 & 308.0911 & -13.4 & $\mathrm{C} 10 \mathrm{H} 17 \mathrm{~N} 3 \mathrm{O} 6 \mathrm{~S}$ & Glutathione & HMDB00125 \\
\hline
\end{tabular}

*ND, not detected

*NF, not found

*HMDB, Human Metabolome Database (http://www.hmdb.ca) 
Table 3. Amino acidic composition of the $<3 \mathrm{kDa}$ permeates isolated from $\mathrm{g}$-IDY and n-IDY preparations

\begin{tabular}{|c|c|c|c|c|}
\hline & g-IDY & & n-IDY & \\
\hline Amino acids $(\mathrm{mg} / \mathrm{L})$ & Mean & $\pm \mathrm{SD}$ & Mean & $\pm \mathrm{SD}$ \\
\hline Free amino acids & 2964 & 342 & 1248 & 22 \\
\hline Free amino acids and peptides & 2865 & 29 & 1604 & 74 \\
\hline Aspartic acid & 19.56 & 0.51 & 18.66 & 0.48 \\
\hline Glutamic acid & 62.21 & 2.31 & n.d. & \\
\hline Asparragine & 7.88 & 0.17 & 5.17 & 0.11 \\
\hline Serine & 15.75 & 0.53 & 6.60 & 0.22 \\
\hline Glutamine & 21.57 & 0.37 & 10.62 & 0.18 \\
\hline Histidine & 24.53 & 0.65 & 56.40 & 1.50 \\
\hline Glycine & n.d. & & 33.15 & 1.08 \\
\hline Threonine & 56.43 & 1.51 & 12.77 & 0.34 \\
\hline Arginine & 8.79 & 0.22 & 6.95 & 0.17 \\
\hline$\beta$-Alanine & 45.82 & 0.32 & 4.43 & 0.03 \\
\hline$\alpha$-Alanine & n.d. & & 3.41 & 0.10 \\
\hline$\gamma$-Aminobutitic acid & 4.01 & 0.14 & 4.05 & 0.14 \\
\hline Tyrosine & 5.70 & 0.08 & 1.05 & 0.01 \\
\hline$\alpha$-Aminobutiric acid & 2.61 & 0.02 & 2.51 & 0.02 \\
\hline Methionine & 1.59 & 0.01 & n.d. & \\
\hline Valine & 2.32 & 0.05 & 1.76 & 0.04 \\
\hline Phenylalanine & n.d. & & n.d. & \\
\hline Tryptophan & n.d. & & n.d. & \\
\hline Isoleucine & 4.38 & 0.11 & 4.67 & 0.11 \\
\hline Leucine & n.d. & & n.d. & \\
\hline Ornithine & 27.75 & 0.48 & 5.43 & 0.09 \\
\hline Lysine & 31.47 & 0.54 & 22.00 & 0.37 \\
\hline
\end{tabular}


Table 4. Tentative identification of the compounds found in the $<3 \mathrm{kDa}$ permeates isolated from $\mathrm{g}$-IDY and n-IDY preparations after FT-ICR-MS analysis.

\begin{tabular}{|c|c|c|c|c|c|c|c|c|}
\hline $\mathrm{m} / \mathrm{z}(\exp )$ & $\mathrm{m} / \mathrm{z}(\mathrm{thr})$ & Error (ppm) & Formula & g-IDY & n-IDY & Tentative ID & METLIN ID & HMDB code \\
\hline 399.1447 & 399.1451 & 1.0 & $\mathrm{C}_{15} \mathrm{H}_{22} \mathrm{~N}_{6} \mathrm{O}_{5} \mathrm{~S}+\mathrm{H}$ & & & S-Adenosylmethionine & 6064 & HMDB01185 \\
\hline 425.1137 & 425.1131 & 1.4 & $\mathrm{C}_{17} \mathrm{H}_{22} \mathrm{~N}_{4} \mathrm{O}_{8} \mathrm{~S}+\mathrm{H}-\mathrm{H}_{2} \mathrm{O}$ & $*$ & & S-(4-Nitrobenzyl)glutathione & 4098 & \\
\hline 425.1364 & 425.1368 & 0.9 & $\mathrm{C}_{15} \mathrm{H}_{26} \mathrm{~N}_{6} \mathrm{O}_{4} \mathrm{~S}+\mathrm{K}$ & $*$ & $*$ & His Cys Lys & 21589 & \\
\hline 427.0949 & 427.0952 & 0.7 & $\mathrm{C}_{13} \mathrm{H}_{22} \mathrm{~N}_{4} \mathrm{O}_{8} \mathrm{~S}_{2}+\mathrm{H}$ & * & & S-Glutathionyl-L-cysteine & 63433 & \\
\hline 431.1416 & 431.1394 & 5.1 & $\mathrm{C}_{20} \mathrm{H}_{26} \mathrm{~N}_{4} \mathrm{O}_{6} \mathrm{~S}-\mathrm{H}_{2} \mathrm{O}-\mathrm{H}$ & & * & Met Asp Trp & 18421 & \\
\hline 453.1675 & 453.1681 & 1.3 & $\mathrm{C}_{17} \mathrm{H}_{30} \mathrm{~N}_{6} \mathrm{O}_{4} \mathrm{~S}+\mathrm{K}$ & $*$ & * & Met Lys His & 21819 & \\
\hline 470.1526 & 470.1479 & 10.0 & $\mathrm{C}_{20} \mathrm{H}_{27} \mathrm{~N}_{5} \mathrm{O}_{5} \mathrm{~S}+\mathrm{Na}-2 \mathrm{H}$ & & * & Tyr His Met & 18106 & \\
\hline 499.1173 & 499.1163 & 2.0 & $\mathrm{C}_{16} \mathrm{H}_{26} \mathrm{~N}_{4} \mathrm{O}_{10} \mathrm{~S}_{2}+\mathrm{H}$ & * & & $\mathrm{N}, \mathrm{N}^{\prime}$-Bis- $\gamma$-glutamylcystine & 63634 & \\
\hline 556.1371 & 556.1379 & 1.4 & $\mathrm{C}_{20} \mathrm{H}_{28} \mathrm{~N}_{7} \mathrm{O}_{9} \mathrm{PS}+\mathrm{H}-\mathrm{H}_{2} \mathrm{O}$ & * & & Biotinyl-5'-AMP & 58228 & HMDB04220 \\
\hline 561.3273 & 561.3235 & 6.8 & $\mathrm{C}_{28} \mathrm{H}_{50} \mathrm{~N}_{4} \mathrm{O}_{3} \mathrm{~S}+\mathrm{K}$ & * & & Oleic Acid-biotin & 45287 & \\
\hline 613.1599 & 613.1598 & 0.2 & $\mathrm{C}_{20} \mathrm{H}_{32} \mathrm{~N}_{6} \mathrm{O}_{12} \mathrm{~S}_{2}+\mathrm{H}$ & $*$ & & Oxidized Glutathione & 45 & \\
\hline
\end{tabular}




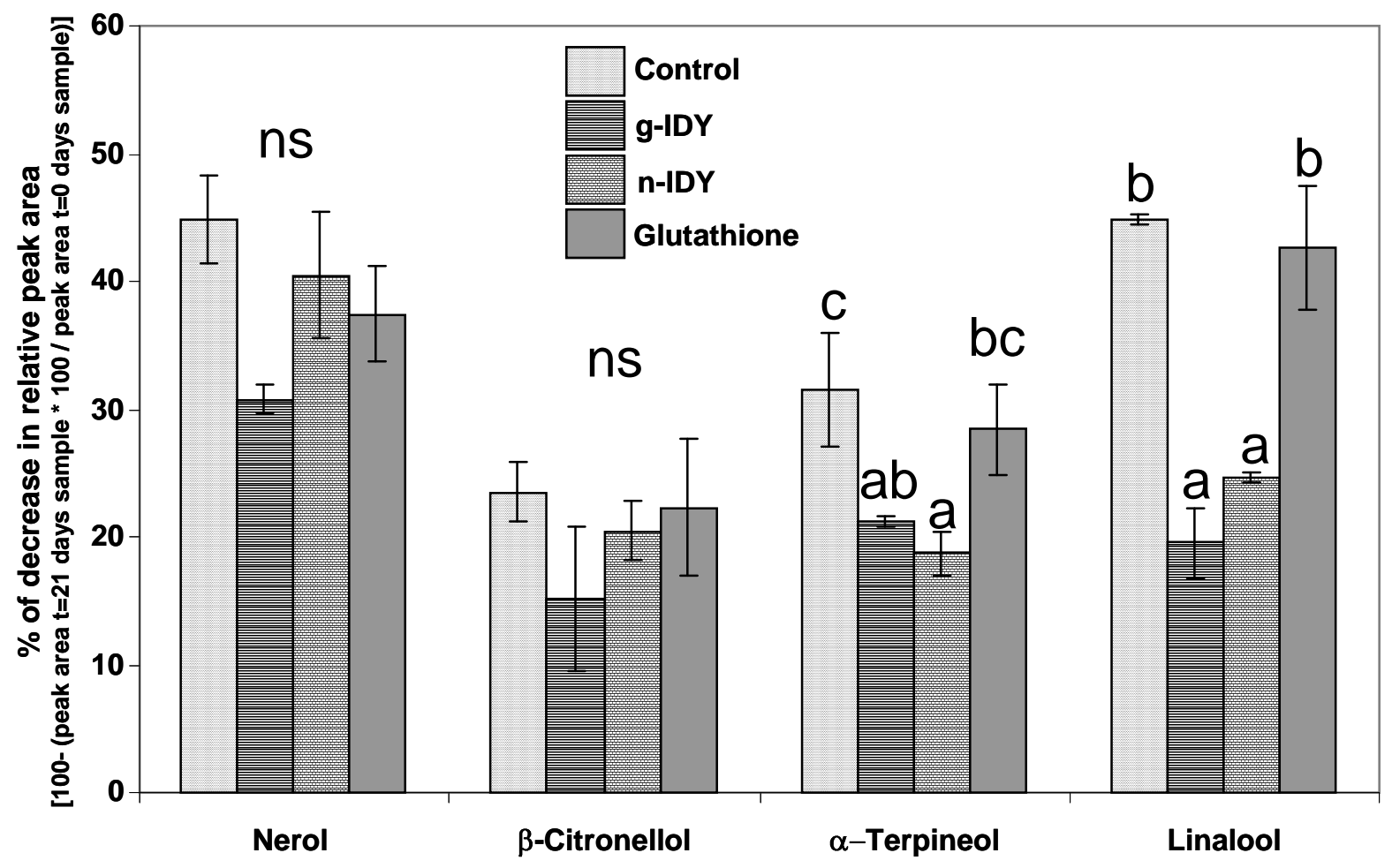

Figure 1 

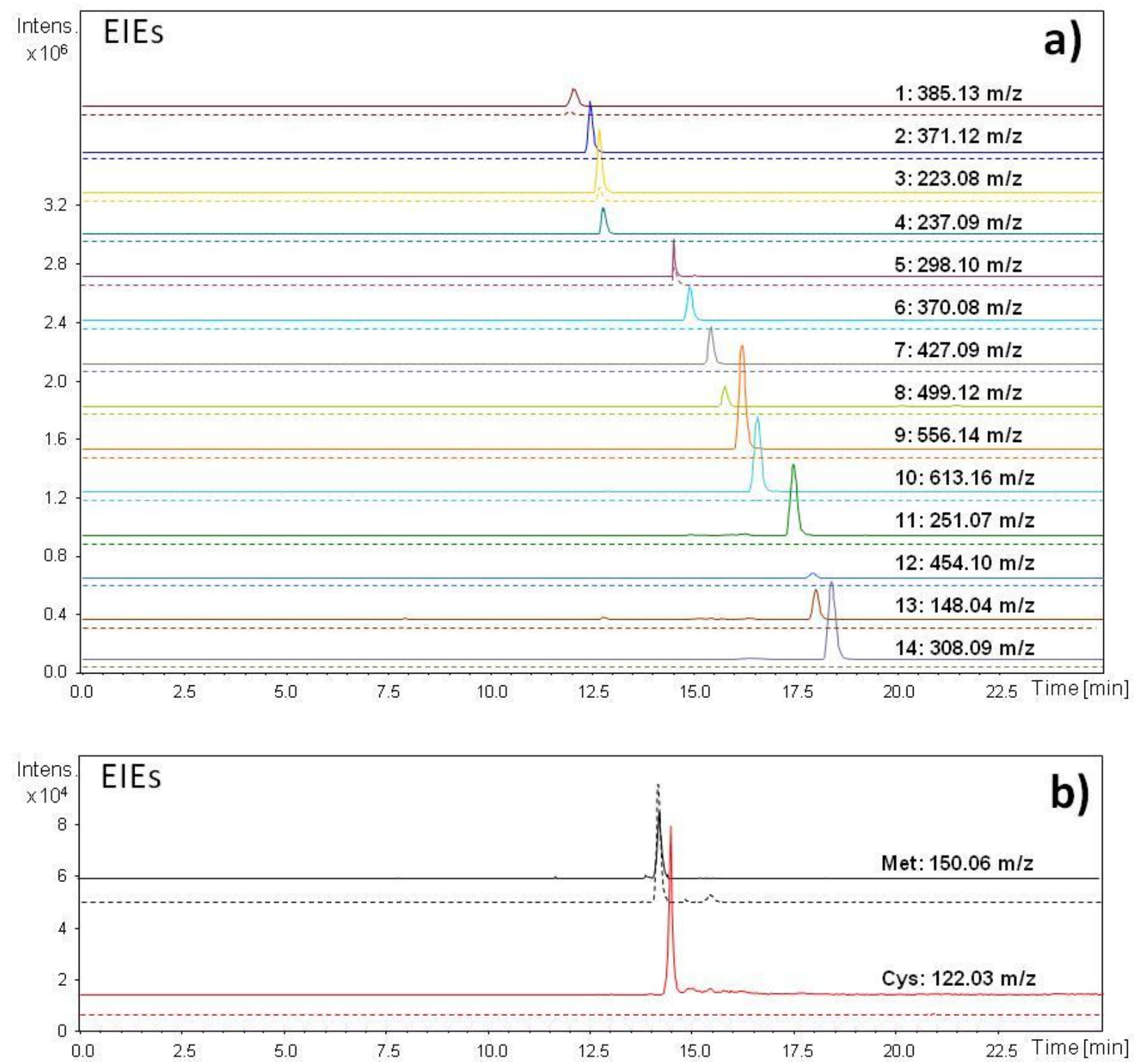

Figure 2 

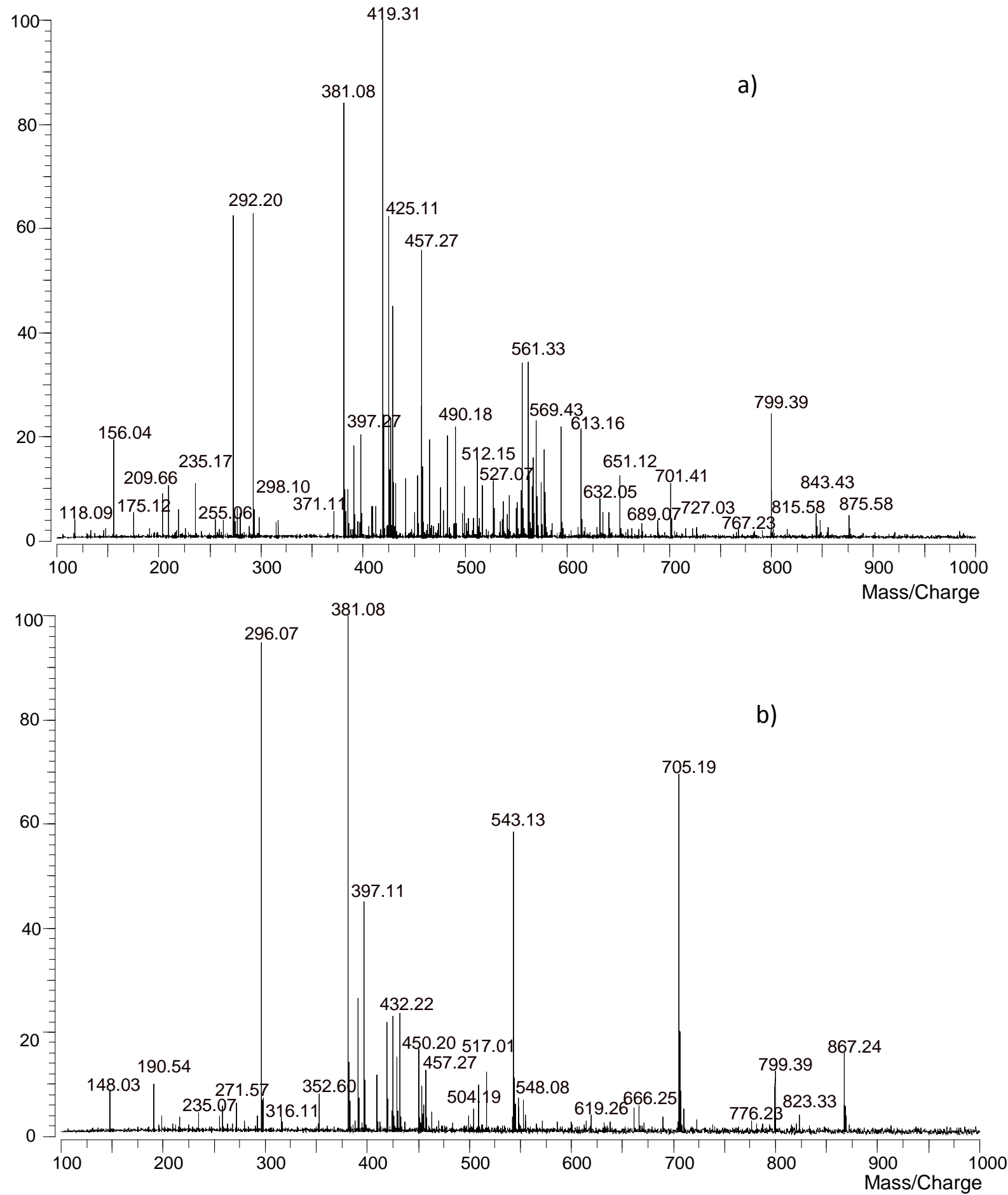

Figure 3. 

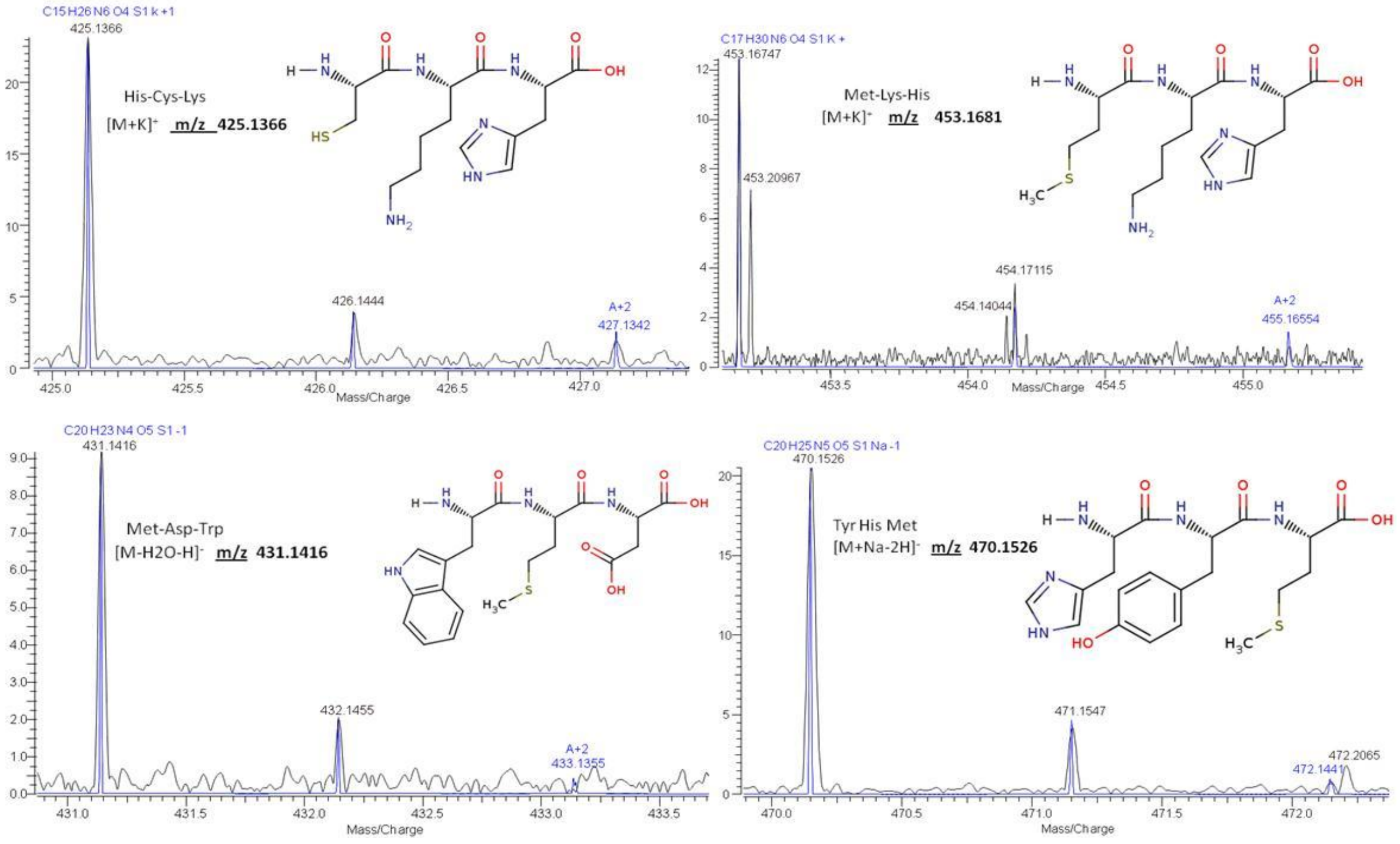
Figure 4 
TOC graphic

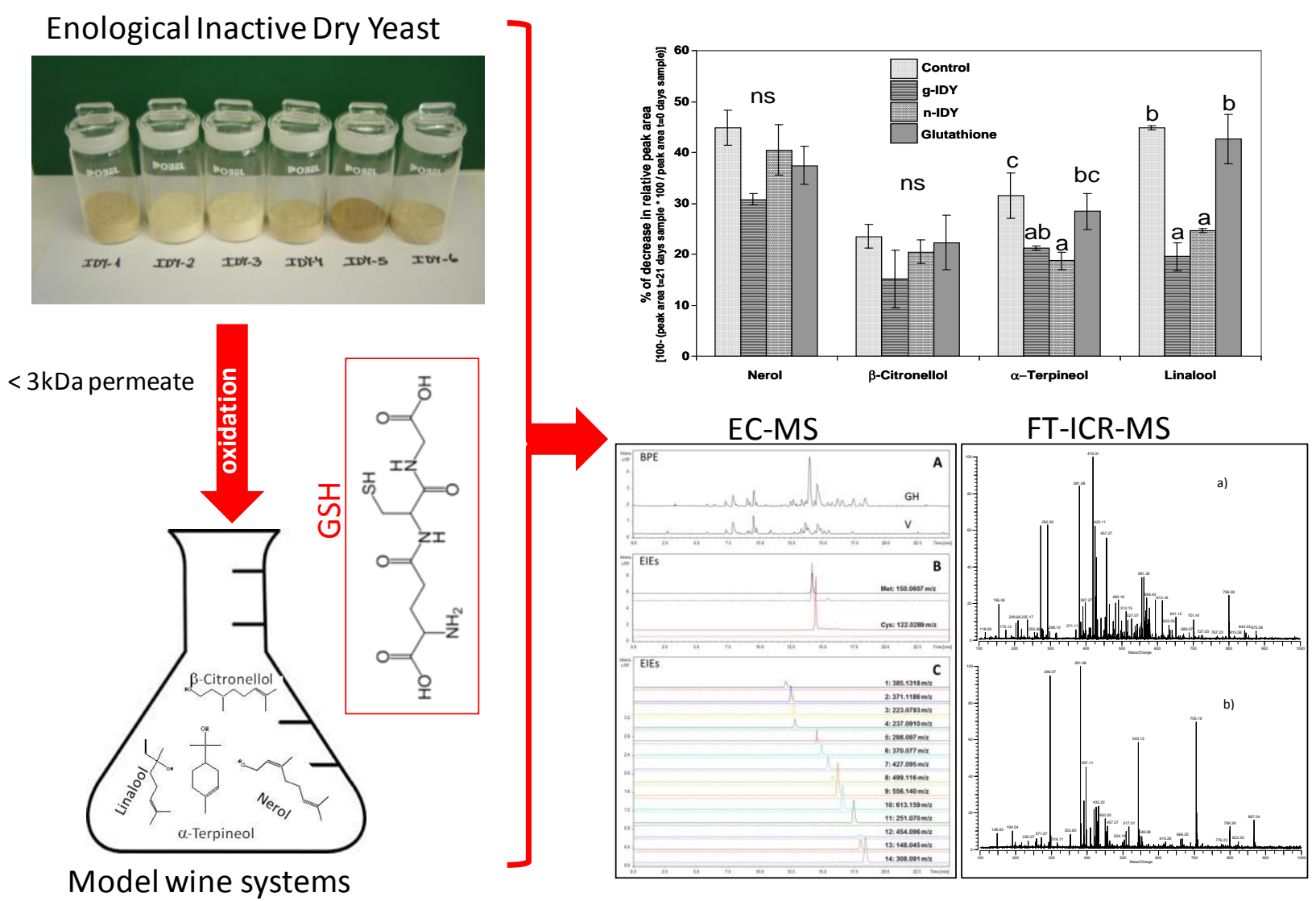

